\title{
The importance of gingival integration in implant-prosthetic oral rehabilitation - preliminary study
}

Mihai BUTUCESCU ${ }^{1}$, Augustin MIHAI ${ }^{1}$, Mihai BURLIBASA ${ }^{1}$, Cosmin MEDAR ${ }^{1}$, Viorel Stefan PERIEANU ${ }^{1}$, Madalina Violeta PERIEANU ${ }^{1}$, Radu COSTEA ${ }^{1}$, Madalina Adriana MALITA ${ }^{1}$, Raluca COSTEA ${ }^{2}$, Corina Marilena CRISTACHE ${ }^{1}$, Maria Glencora COSTACHE ${ }^{1}$, Magdalena Natalia DINA ${ }^{1}$, Simion Gheorghe DUMITRU ${ }^{1}$, Irina Adriana BEURAN ${ }^{1}$, Oana-Cella ANDREI ${ }^{1}$, Gabriela TANASE ${ }^{1}$

1"Carol Davila” University of Medicine and Pharmacy, Bucharest, Romania

${ }^{2}$ Dental Practice, Brasov, Romania

\begin{abstract}
Gingival integration, also known as epithelio-conjunctive integration, together with bone integration, is one of the main processes involved in the tissue integration of dental implants. Unfortunately, many practitioners treat this gingival integration with great superficiality, considering it to be an insignificant factor in this highly complex process of tissue integration of dental implants.

Purpose. In this study, we intend to define very precisely the concept of "gingival integration" or "epithelial-conjunctive integration" and to introduce it as a specialized term in the basic vocabulary of implantologists.

Material and method. A questionnaire based on 5 questions was used to carry out this study. The study group was composed of 64 implantologist (all subjects are holders of a degree after following a competence program in oral implantology in Bucharest). The study was conducted between October 2015 and November 2018.

Results and discussions. The responses of the 64 practitioners have been analyzed and structured for a simple understanding, being extremely important for future research directions.

Conclusions. Following the analysis of the results of this study we consider that the concept of "gingival integration" of dental implants requires more attention from practitioners, which will be reflected in the long-term success of dental implants.
\end{abstract}

Keywords: gingival integration, epithelio-conjunctive integration, tissue integration, dental implants

\section{INTRODUCTION}

It is known that dental implants are currently one of the most important alternatives for re- placing lost teeth. Thus implanto-prosthetic oral rehabilitation involves both the summing up of knowledge in the field of implant surgery and dental prosthetics, both of which are necessary 
for the long-term success of dental implants. Thus implanto-prosthetic oral rehabilitation involves the summing up of knowledge in the field of implantation surgery and dental prosthetics, both of which are necessary for the long-term success of dental implants.

But the tissular integration of dental implants involves the combination of two extremely important processes, namely: bone integration and gingival integration (or epithelial-conjunctive integration). In order to accomplish these two processes, but also for the long-term maintenance of the implant-supported restoration, we need a very good acquirement of current knowledge in the field (110).

\section{GENERAL DATA}

As we mentioned in the introductory part of this paper, for achieving the aims of oral implantology, it is of great importance to obtain the tissue integration of dental implants. Tissular integration is the morphological and functional coexistence between the bone and the surface of the implant subjected to occlusal forces. However, the insertion of dental implants is done in two types of tissues, bone or gingival, a successful treatment impose compulsory achieving and maintaining equally two types of integration: bone and gingival (or epithelial-conjunctive), without considering one more important than the other (1-9).

But, before going to the actual description of this study, it is necessary to clarify these concepts very briefly, and we consider them to be extremely important (1-10):

1. Bone integration is designed to rigidly fix the dental implant to the support bone while ensuring the transfer of the masticatory forces to the neighboring bone. This is achieved by the use of a suitable surgical technique by providing the primary stability of the dental implant and by appropriate implant-supported prosthetic rehabilitation, limiting the movements at the bone-implant interface, thus allowing healing around the implant.

2. Gingival integration is intended to create a soft tissue barrier around the dental implant, with the role of protecting the underlying bone and avoiding access to micro-organisms. The soft tissue surrounding the dental implants is known as the peri-implant mucosa, and the interface area between the implant and the mucosa is made up of an epithelial component and a conjunctive tissue component, therefore the term of epithelial-conjunctive integration. The epithelial area is also called an epithelial barrier and is similar to the junctional epithelium around the natural teeth. The epithelial tissue attachment, which occurs around the implant cervix, is a unique structure in the body that is no longer found elsewhere. But, dental implants are also unique structures in the body, compared to other medical devices, by the fact that they penetrate an epithelium. (11-15)

Peri-implant tissues are, however, similar to periodontal tissues, both structural and functional. A better understanding of the interface microstructure between the soft tissue and dental implant will help the clinician to better choose an implant system and to achieve lasting clinical success. (16-20)

\section{PURPOSE OF THE STUDY}

Just as important as bone integration is gingival integration (or epithelial-conjunctive integration) to achieve the success of a dental implant. This epithelial-conjunctive integration is actually accomplishing a perimucosal seal at the soft tissue - implant interface. Thus, the implant crosses the mucosa, without allowing the access of bacteria to soft tissues, thanks to the achievement of a periimplantary ring at this level, which protects the underlying tissues. The periimplantary ring consists of collagen fibers, which are circumferentially arranged around the implant. At this level, the soft tissue is made up of the sulcus epithelium, the junctional epithelium and the underlying conjunctive tissue, rich in collagen fibers. Unfortunately, most of implantologists completely ignore this aspect of epithelial-conjunctive integration, focusing only on bone integration of the dental implant (primary bone integration - which is from the insertion of the implant to mounting of prosthetic abutment and functional secondary bone integration - which begins with implant-supported prosthetic restorations that generates bone resorption and bone remodeling in the newly formed bone, with the reorganization of the bone laminae on the applied forces line, in parallel with a condensation of the neoalveolar wall), bone integration that can be well monitored by very accurate radiological exams (110).

The radiological exam (retroalveolar radiography, orthopantomogram or panoramic radiography, CT scan) is considered the most impor- 
tant diagnostic aid in dental medicine. In oral implantology, radiological examination is useful both for the insertion of the dental implant and for monitoring the progress and preventing possible complications. For dental implant monitoring, implantologists consider completely different aspects, completely ignoring this very important epithelial-conjunctive integration (110):

- Bone healing;

- Peri-implant bone level and possible bone loss;

- Eventual occurrence of peri-implant pathology (peri-implantitis);

- Correct insertion of the prosthetic abutment in the implant;

- Maintaining the abutment adjustment to the prosthetic superstructure;

- The possibility of fracture of the implant or prosthetic work.

As a rule, a correct assessment of the gingival (or epithelial-conjunctive) insertion of dental implants can be clinically performed visually by analyzing the following parameters (1-10):

- The aspect of the peri-implant mucosa: color, contour, aspect of the interdental papilla;

- With the help of the periodontal probe, with which it can be determined:

- The depth of the peri-implant sulculus;

- The degree of bleeding, the presence of exudate and / or suppurations that may occur following the probing.

Starting from the aforesaid, we can specify that the purpose of this study, even if it is a preliminary one, is the implementation among implantologists of the "gingival integration" or "epithelial-conjunctive integration" term as a distinct medical term in the tissue integration process of dental implants.

\section{MATERIAL AND METHOD}

The gingival or epithelial-conjunctive integration of dental implants results in sealing between the external environment formed by the oral cavity and the internal environment, defined mostly by the bone in which the dental implant is inserted. The gingival integration of the dental implant is a very important factor and a reference to the longevity of its function, this integration being a physiological barrier between the internal and the external environment and must be efficient enough to seal the communication between the two environments (1-10).
Starting from the notions presented in the first part of this material, we composed a questionnaire of 5 items, which we applied to a number of 64 implantologists in order to implement the term "gingival integration" or "epithelial-conjunctive integration", as a distinct term in the process of tissue integration of dental implants. All subjects are holders of a degree after following a competence program in oral implantology, diploma obtained during 2007-2017, competence program held in Bucharest. In Bucharest, there were two permanent programs of competence in oral implantology in the period 2007-2017, each with a different manager. In our case, by implantologists we have referred to absolutely all the dental practitioners who are involved in the implant-prosthetic rehabilitation process without making any distinction: both those who perform the dental implant insertion surgery and those who perform implant-supported prosthetic rehabilitation. But, as we will see from statistic determination, many of the implantologists handles all stages specific to the clinical department in implanto-prosthetic oral rehabilitation (both surgical and prosthetic times).

Thus, of the 64 implantologist, 46 (representing $71.88 \%$ ), are dentists performing full implanto-prosthetic rehabilitation (both surgical and prosthetic times in the clinical compartment), 10 of them (representing 15.62\%) only performs the dental implant insertion times, and the remaining 8 subjects (representing $12.50 \%$ ) only perform prosthetic times in the clinical compartment of the implant-supported restorations (Fig. 1).

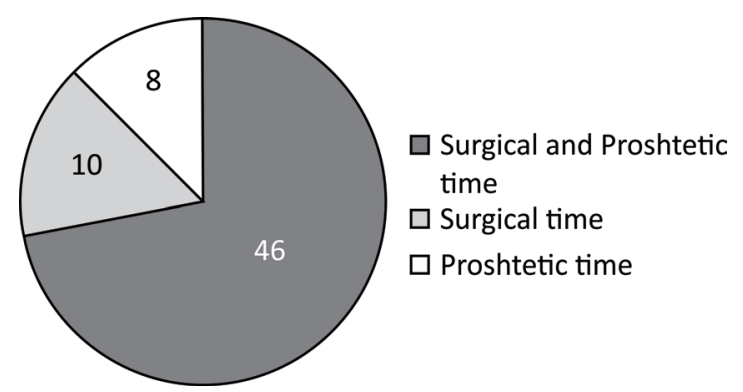

FIGURE 1. Percentage distribution of practitioners according to the specificity of the work they perform in implant-prosthetic rehabilitation

Of the 64 subjects involved in the study, 41 (representing 64.06\%) were female, while the remaining 23 subjects (representing 35.94\%) are male (Fig. 2). 


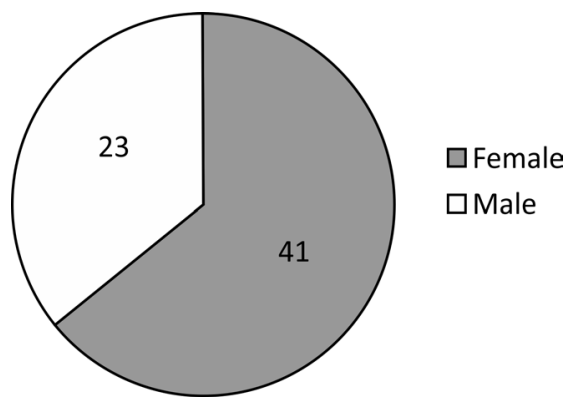

FIGURE 2. Gender distribution of the subjects involved in the study.

Next, we will present the questionnaire applied to the 64 subjects, as well as the right answers:

\section{Questionnaire}

1. Tissue integration of dental implants involves: $\boldsymbol{a}$. Only bone integration; $\boldsymbol{b}$. Only gingival integration (or epithelial-conjunctive integration); c. Summing up the two processes: bone integration and gingival integration (or epithelial-conjunctive integration)?

\section{Correct answer: $c$.}

2. The role of gingival integration (or epithelial-conjunctive integration) is: $\boldsymbol{a}$. To create $a$ soft tissue barrier around the dental implant; $\boldsymbol{b}$. Protect the underlying bone and avoid access to micro-organisms; $\mathrm{c}$. Filter the essential ions ( $\mathrm{Ca}$, $\mathrm{K}, \mathrm{Mg}$ ) for functioning of the peri-implant gingival mucosa.

\section{Correct answers: $\boldsymbol{a}, \boldsymbol{b}$.}

3. Gingival (or epithelial-conjunctive) integration of dental implants can be tracked: $a$. Radiologically with OPG; $b$. Clinically, visual, following the appearance of the peri-implantation mucosa: color, contour, aspect of the interdental papilla; c. Clinically, with the help of the periodontal probe, determining the depth of the peri-implant sulculus, the degree of bleeding, the presence of exudate and / or the suppurations that may occur after the probing?

\section{Correct answers: $b, c$.}

4. Do you think that in the dental implant monitoring process, to the issues mentioned at the beginning of the study, the gingival integration process (epithelial-conjunctive integration) should be added? a. Yes; b. No; $c$. From time to time?

\section{Correct answer: $a$.}

5. Do you think that the notion of "gingival integration" and/or "epithelial-gingival integration" should be implemented as a key term in the implantologists language regarding the tis- sue integration process of dental implants: $a$. Yes; b. No; $c$. In some particular situations?

\section{Correct answer: $a$.}

\section{RESULTS AND DISCUSSIONS}

The responses provided by the 64 participants in the study were centralized and processed as follows:

Among the practitioners involved in the implant-prosthetic rehabilitation process the perception on tissue integration of dental implants is the following: 49 subjects involved in the study $(76.56 \%)$ responded correctly, bone and gingival integration, while only 15 subjects (23, $44 \%$ ) responded wrong, only bone integration (Fig. 3).

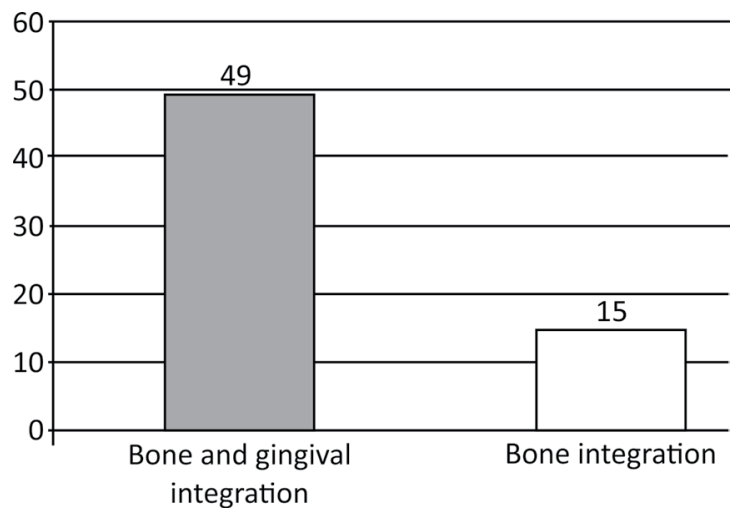

FIGURE 3. The perception of practitioners on the tissular integration of dental impulses

Regarding the role of gingival integration, 42 of the subjects involved in the study (representing $65.63 \%$ ) responded correctly (response variants $\boldsymbol{a}$ and $\boldsymbol{b}$ ) while the 22 subjects (representing $34.37 \%$ ) selected other variants (Fig. 4).

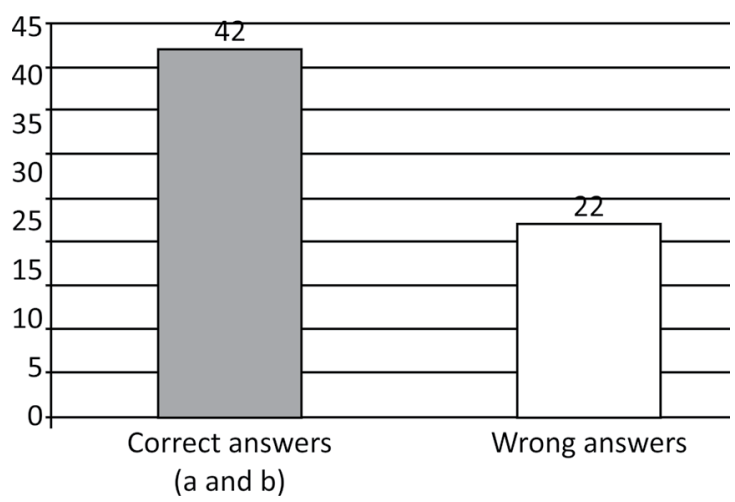

FIGURE 4. The role of gingival integration of dental implants.

Concerning the tracking in time of gingival integration of dental implants only 5 of the subjects involved in the study $(7.81 \%)$ responded 
correctly (variant b and c.), the remaining 59 subjects (92.18\%) provided incorrect answers (Fig. 5).

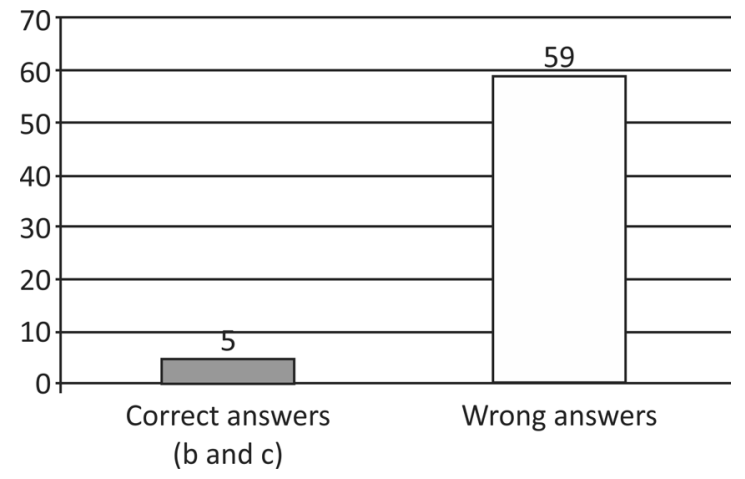

FIGURE 5. Tracking in time of gingival integration of dental implants.

Concerning the last two questions related to the follow-up of the gingival integration process and the implementation of the gingival integration concept in the language of the practitioners involved in the implant-prosthetic rehabilitation process all subjects answered correctly, which shows an openness towards understanding and applying the measures leading to the success on long-term of dental implants.

\section{CONCLUSIONS}

Although all implantologists involved in the study are holders of a degree after following an oral implantology program in Bucharest, only 49 of them $(76.56 \%)$ are aware that the tissue integration of dental implants involves summing up the two processes: bone integration and gingival integration (or epithelial-conjunctive integration). This implies several possibilities, namely:

- The existence of two programs of competence in oral implantology in Bucharest at the same time, with different managers, does not automatically mean a uniformity of the knowledge passed to the trainees;

- Misconduct of these notions;
- The unacquiring of these notions by those trainees, due either to a certain degree of superficiality or to the indifference with which they treated the theoretical part, at the expense of a more consistent practice activity.

The answers given to the second question connected to gingival integration come to fully confirm the first conclusion of this preliminary study.

Almost all implantologists involved in the study believe that the OPG investigation can assess the degree of gingival integration of dental implants, which is in contradiction to the literature and confirms the authors' opinion.

The subjects involved in the study believe that monitoring of the gingival integration process (epithelial-conjunctive integration) should be added to the dental implant monitoring process. In fact, as we mentioned in the first part of the study, a correct assessment of the gingival (or epithelial-conjunctive) insertion of the dental implants can be done clinically, visually by analyzing the following clinical parameters: the peri-implant mucosa (color, contour, appearance of interdental papilla); with the help of the periodontal probe (it is possible to determine the depth of the peri-implant sulculus, the degree of bleeding, the presence of exudate and / or the suppurations that can occur after the probing). These maneuvers are done by a thorough practitioner, they are simple, useful and which does not consume much time, but they have to go into the routine of any professional.

All subjects involved in the study believe that the notion of "gingival integration" and / or "epithelial-gingival integration" should be implemented as a key term in implantologists' language in terms of tissue integration of dental implants.

\section{ACKNOWLEDGEMENT}

In this article, all the authors have equal contributions with the first author.

Conflict of interest: none declared Financial support: none declared

\section{REFERENCES}

1. Fonseca RJ, Frost DE, Powers MP et al. Oral and maxillofacial surgery. Volume 7; St Louis: Saunders, 2000.

2. Weber HP, Cochran DL. The soft tissue response to osseointegrated dental implants. Journal of Prosthetic Dentistry. 1998, Volume 79, No. 1, p. 79-89.

3. Marchetti C, Farina A, Cornaglia Al. Microscopic, immunocytochemical, and ultrastructural properties of peri-implant mucosa in humans. Journal of Periodontology. 2002, 73: 555-563.

4. Berglundh T, Lindhe J, Ericsson I et al. The soft tissue barrier at implants and teeth. Clinical Oral Implants Research. 1991, 2, 81-90. 
5. Cawson RA, Odell E.W. Cawson's essentials of oral pathology and oral medicine. Edition: 8, illustrated; Philadelphia: Ed. Elsevier's Health Sciences, Philadelphia, 2008.

6. Listgarten MA, Lai $\mathrm{CH}$. Ultrastructure of the intact interface between an endosseous epoxy resin dental implant and the host tissues. Journal de Biologie Buccale. 1975, 3: 13-28.

7. Fujiseki M, Matsuzaka K, Yoshinari M et al. An experimental study on the features of peri-implant epithelium: immunohistochemical and electronmicroscopic observations. The Bulletin of Tokyo Dental College. 2003, 44: 185-199.

8. Miloro M, Ghali GE, Larsen PE et al Peterson's principles of oral and maxillofacial surgery. Edition: 2, illustrated; Hamilton, Ontario: BC Decker Inc, 2004.

9. Wray D, Stenhouse D, Lee D, Clark AJE, Textbook of general and oral surgery. Edition: illustrated; London: Churchill Livingstone, 2003.

10. Esposito M, Hirsch JM, Lekholm U Biological factors contributing to failures of osseointegrated oral implants. II. Etiopathogenesis; European Journal of Oral Sciences. 1998, 106: 721-764.

11. Burlibașa $L$, Zarnescu $O$. In vivo effects of Trichostatin A-A histone deacetylase inhibitor-On chromatin remodeling during Triturus cristatus spermatogenesis. Animal reproduction science. 2013, 142 (1-2), 89-99.

12. Gavrila L, Mircea L. Chromatin and chromosomal fine structure in spermatogenesis of some species of amphibians. Zygote. 2001, 9(3), 183-192.

13. Ștețiu AA, Oleksik M, Oleksik V et al. Mechanical behavior of composite materials for dental obturations. Romanian Biotechnological Letters. 2013, 18(4), p. 8528-8538.

14. Bodnar DC, Pantea M, Bodnar T et al. Patologia mucoasei orale la pacienţii vârstnici-studiu clinico-statistic. Acta Medica Transilvanica. 2012, 2(2), p. 56-60.

15. Cristache CM, Burlibașa M, Cristache G. et al. Zirconia and its biomedical applications. Metalurgia International. 2011, 16(7), 18, p. $18-23$.
16. Bodnar DC, Dimova C, Bodnar T et al. Dental management of patient with psychiatric disorders. Modern Medicine. 2010, 17(10), p. 538-543.

17. Lazăr V, Chifiriuc C, Bucur M et al. Investigation of dental-plaque formers biofilms by optic and confocal laser scanning microscopy and microbiological tool. Revista Medico-Chirurgicală a Societăti de Medici si Naturalitti din lasi. 2008, Vol. 112, No. 3, p. 812-820.

18. Burlibașa M, Muntianu LAS, Tănase $G$ et al. Study on microbial contamination of biomaterials in medical practice. Metalurgia International. 2010, 15, p. 163-166.

19. Burlibașa $M$, Cuculescu $M$, Tănase $G$ et al. Dental alloys of prothetic use - A retrospective of their use in Romania. Metalurgia International. 2009, 14, p. 51-53.

20. Burlibașa L, Gavrila L. Developmental epigenetics: roles in embryonic development, In: Niculescu MD, Haggarty P.: Nutrition in Epigenetics, Hoboken, New Jersey: Willey-Blackwell Publishing, 2011, Ch. 6, p. 105-126. 